2723-7583 (Online)

\title{
STUDI KERENTANAN WILAYAH DAN KETAHANAN MASYARAKAT PESISIR KECAMATAN GEDANGAN KABUPATEN MALANG TERHADAP BENCANA TSUNAMI
}

Study Vulnerability And Resilience Of Coastal Areas Subdistrict Gedangan, Malang Of Tsunami

\author{
Syafrianida Anwar ${ }^{1 \star}$ dan Zainul Hidayah² \\ ${ }^{1}$ Mahasiswa program Studi IImu Kelautan, Universitas Trunojoyo Madura \\ ${ }^{2}$ Dosen Program Studi IImu Kelautan, Universitas Trunojoyo Madura \\ *Corresponding author email: syafrianidaanwar@gmail.com
}

Submitted: 10 February 2020 / Revised: 27 February 2020 / Accepted: 27 February 2020

http://doi.org/10.21107/juvenil.v1i1.6722

\begin{abstract}
The Indonesian archipelago is on track subduction tectonic plates, the existence of this subduction process causes the Indonesian archipelago is prone to earthquakes both low and high strength. Collisions or harsh shifting plates accompanied by an earthquake in the ocean area would pose a potential tsunami. South Coastal Malang is one of the areas prone to tsunamis. This study aims to determine the vulnerability of the area and the resilience of coastal communities Gedangan subdistrict, Malang against tsunami. The method used in the determination of the class of vulnerabilities is by the method weighted overlay with the four elements, namely the vulnerability of the land elevation, slope, distance from the beach and the distance from the river. The results of the study showed that vulnerability was very low susceptibility $188.63 \mathrm{Ha}, 7470.46 \mathrm{Ha}$ low, medium 1026.63 Ha, 649.72 Ha high, and very high $201.38 \mathrm{Ha}$, with a total area of $9536.84 \mathrm{Ha}$. The method used in the determination of community resilience using CCR (Coastal Community Resilience). CCR method is a method that is performed to determine communities' resilience in the face of disaster by distributing questionnaires and scoring. CCR resistance element is composed of government, social and economic life, coastal resource management, structural design and land use, knowledge of the risks, warning and evacuation, emergency response, and recovery after a disaster. RESULTS resistance element that is below standard (3) is a government elements (2,62), social and economic life (2.66), the design of the structure and land use (2.51) and disaster recovery (2.35). Thus the need for recommendations to improve community resilience element so that in accordance with the standards.
\end{abstract}

Keywords: Tsunami, Vulnerability, Resilience, Malang

\section{ABSTRAK}

Kepulauan Indonesia berada di jalur lempeng tektonik subduksi, keberadaan proses subduksi ini menyebabkan kepulauan Indonesia rentan terhadap gempa bumi baik kekuatan rendah maupun tinggi. Tabrakan atau pergeseran lempeng yang keras dan disertai dengan gempa bumi di wilayah lautan akan berpotensi tsunami. Pesisir Selatan Malang adalah salah satu daerah yang rawan tsunami. Penelitian ini bertujuan untuk mengetahui kerentanan wilayah dan ketahanan masyarakat pesisir Kecamatan Gedangan, Malang terhadap tsunami. Metode yang digunakan dalam penentuan kelas kerentanan adalah dengan metode overlay dengan empat elemen, yaitu kerentanan ketinggian tanah, kemiringan lereng, jarak dari pantai dan jarak dari sungai. Hasil Penelitian menunjukkan kerentanan sangat rendah 188,63 Ha, rendah 7470,46 Ha, menengah 1026,63 Ha, tinggi 649,72 $\mathrm{Ha}$, dan sangat tinggi 201,38 Ha, dengan total area 9536,84 Ha. Metode yang digunakan dalam penentuan ketahanan masyarakat menggunakan CCR (Coastal Community Resilience). Metode CCR adalah metode yang dilakukan untuk mengetahui ketahanan masyarakat dalam menghadapi bencana dengan membagikan kuesioner dan skoring. Elemen resistensi CCR terdiri dari kehidupan pemerintah, sosial dan ekonomi, pengelolaan sumber daya pesisir, desain struktural dan penggunaan lahan, pengetahuan tentang risiko, peringatan dan evakuasi, tanggap darurat, dan pemulihan setelah bencana. Hasil elemen resistensi yang di bawah standar (3) adalah elemen pemerintah (2,62), kehidupan sosial dan ekonomi $(2,66)$, desain struktur dan penggunaan lahan $(2,51)$ dan pemulihan bencana $(2,35)$. Maka dari itu perlu 
adanya rekomendasi untuk meningkatkan elemen ketahanan masyarakat sehingga sesuai dengan standar.

Kata kunci: Tsunami, Kerentanan, Ketahanan, Malang

\section{PENDAHULUAN}

Wilayah negara Indonesia berada antara $6 \circ \mathrm{LU}$ - 110 LS dan 95० - $141^{\circ}$ BT. Posisi wilayah negara Indonesia yang terletak di khatulistiwa menyebabkan wilayah Indonesia ini beriklim tropis. Namun disamping itu, ada beberapa kondisi dari letak wilayah Indonesia yang menjadikan wilayah Indonesia ini rawan bencana (Munir, 2014). Geologis pulau-pulau di Indonesia ada pada jalur penumjaman lempeng bumi, diantaranya penunjaman Lempeng IndoAustralia dengan Lempeng Benua Eurasia yang berada di sepanjang pantai bagian barat Pulau Sumatera hingga pantai bagian selatan Pulau Jawa hingga ke timur sampai Kepulauan Nusa Tenggara. Dengan terdapatnya proses penunjaman lempeng bumi ini menyebabkan Kepulauan Indonesia terdapat banyak gunung api, terutama di wilayah Sumatera, Jawa sampai Nusa Tenggara (Nur, 2010). Posisi ini yang menjadikan wilayah negara Indonesia sangat rawan akan bencana alam yaitu bencana gempa bumi, dalam skala rendah maupun tinggi. Penunjaman lempeng yang keras dan diikuti dengan gempa yang bersumber dari perairan laut akan menimbulkan potensi bencana tsunami.

Wilayah yang berpotensi terjadi bencana tsunami adalah pesisir selatan Jawa, satu diantaranya yaitu pesisir selatan Malang. Kabupaten Malang adalah salah satu kabupaten yang terletak di selatan Pulau Jawa. Daerah bagian selatan Kabupaten Malang umumnya dikenal dengan sebutan "Pantai Selatan Malang" merupakan gugusan pantai yang memiliki pemandangan yang sangat indah, tidak heran jika hampir seluruh pantai yang ada di Kabupaten Malang telah dikelola pemerintah daerah sebagai obyek wisata. Kecamatan Gedangan adalah salah satu kecamatan di Kabupaten Malang yang memiliki wilayah pesisir. Kecamatan Gedangan memiliki kurang lebih 7 pantai yang kini telah dikelola pemerintah dan masyarakat sekitar untuk menjadi obyek wisata. Jumlah kepadatan penduduknya mencapai 493 jiwa/km2 (Kecamatan Gedangan dalam Angka, 2018).

Kondisi kawasan pesisir Kecamatan Gedangan yang menghadap langsung ke Samudera Hindia mempunyai potensi rawan akan bencana tsunami, perlu adanya studi mengenai tingkat kerentanan dan ketahanan masyarakat pesisir Kecamatan Gedangan terhadap bencana tsunami. Studi tersebut dilakukan dalam bentuk upaya mitigasi guna meminimalisir dampak dari bencana. Perumusan upaya mitigasi diharapkan dapat menjadi pendoman dalam mengantisipasi bila terjadi bencana tsunami di wilayah pesisir Kecamatan Gedangan, Kabupaten Malang.

\section{Waktu dan Tempat}

\section{MATERI DAN METODE}

Lingkup wilayah dalam penelitian ini adalah Desa Tumpakrejo, Desa Sindurejo, dan Desa Gajahrejo Kecamatan Gedangan, Kabupaten Malang (Gambar 1). Luas daerah tersebut secara berurutan yaitu Desa Tumpakrejo dengan luas $2494 \mathrm{Ha}$, Desa Sindurejo dengan luas 1898,9 Ha, dan Desa Gajahrejo dengan luas $1903 \mathrm{Ha}$. Kecamatan Gedangan terletak diantara 112,3521-122,3945 bujur timur dan 8,2231-8,1448 lintang selatan. Kecamatan Gedangan berjarak sekitar $27 \mathrm{~km}$ dari ibukota Kabupaten Malang. Luas Kecamatan Gedangan sebesar $130,55 \mathrm{~km} 2$ atau sekitar $4,38 \%$ dari luas total Kabupaten Malang dengan kepadatan penduduknya $406 \mathrm{jiwa} / \mathrm{km} 2$ (Kecamatan Gedangan dalam Angka, 2018). Metode yang digunakan adalah pengolahan data sekunder berupa data parameter dan pengolahan data primer berupa kuesioner. 


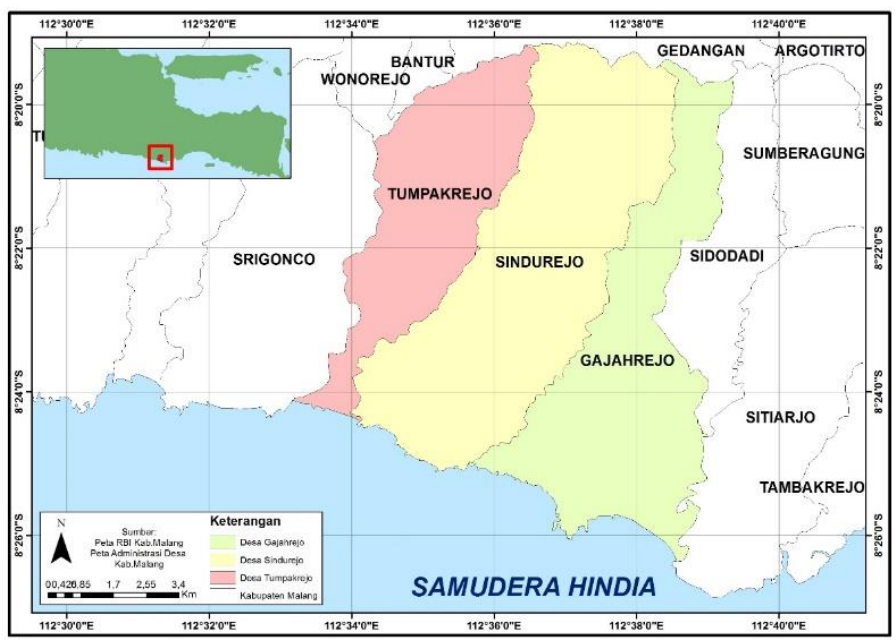

Gambar 1. Peta Lokasi Penelitian

\section{Alur Penelitian}

Parameter-parameter kerentanan yang digunakan adalah jarak dari garis pantai, ketinggian, wilayah lereng, serta jarak dari sungai. Parameter tersebut kemudian dioverlay untuk menaksir tingkat bahaya tsunami di daerah tersebut. Overlay dilakukan dengan metode skoring dan pembobotan. Data ketinggian dan wilayah lereng diperoleh dari pengolahan Citra ASTER (The Advanced Spaceborne Thermal Emission and Reflection Radiometer) GDEM (Global Digital Elevation Model) yang diunduh di https://earthexplorer.usgs.gov/. Selain itu, data jarak dari sungai dan jarak dari garis pantai diperoleh dengan mengunduh data peta RBI Kabupaten Malang di https://tanahair.indonesia.go.id/ dengan skala 1:25.000. Sedangkan untuk data primer ketahanan masyarakat dengan melakuakan kuesioner yang merujuk pada metode CCR yang dikemukakan oleh NOAA (National Oceanic \& Atmospheric Administration), disponsori oleh USAID (United States Agency for International Development) dan termasuk dalam program US-IOTWS (U.S. - Indian Ocean Tsunami Warning System).

\section{Pengolahan Data Kerentanan}

Adapun parameter-parameter kerentanan yang digunakan menurut Hadi dan Damayanti, (2017) diolah sebagai berikut

a. Jarak dari garis pantai

b. Ketinggian daratan

c. Wilayah lereng

d. Jarak dari sungai

Parameter-parameter tersebut selanjutnya diolah menggunakan Aplikasi Arc Gis untuk mendapatkan peta kerentanan

\section{Ketahanan Masyarakat}

Faktor yang menyebabkan banyaknya korban jiwa serta kerugian harta benda ketika terjadi bencana adalah kurangnya pemahaman masyarakat mengenai bencana dan kesiapsiagaan dalam menghadapi bencana. Maka perlu dilakuakannya studi mengenai ketahanan masyarakat pesisir Kecamatan Gedangan, Kabupaten Malang terhadap bencana tsunami. Metode Coastal Community Resilience (CCR) adalah metode yang dilakukan untuk mengetahui ketahanan masyarakat dalam menghadapi bencana. Metode CCR dikemukakan oleh NOAA (National Oceanic \& Atmospheric Administration), disponsori oleh USAID (United States Agency for International Development) dan termasuk dalam program US-IOTWS (U.S. - Indian Ocean Tsunami Warning System).

Metode penilaian ketahanan masyarakat pesisir pada penelitian ini menggunakan kuesioner dan wawancara dengan metode sampling berupa stratified sampling dan purposive sampling. Menurut Prijana, (2005) stratified sampling lebih presisi dalam penentuan respondennya, karena tiap strata dianggap memiliki populasi sendiri dan analisis tiap stratanya dapat dilakuakan tanpa harus survey ulang. Elemen ketahanan yang ada, akan diadaptasi menjadi beberapa pertanyaan yang dapat digunakan sebagai instrument survey untuk memantau kapasitas ketahanan. Sedangkan metode purposive sampling dilakuakan dengan pengambilan sampel dengan cara menetapkan ciri-ciri khusus yang sesuai dengan tujuan penelitian sehingga diharapkan dapat menjawab permasalahan penelitian. Seluruh hasil pengolahan parameter kerentanan dan ketahanan masyarakat mengahasilkan data kerentanan wilayah dan 
ketahanan masyarakat pesisir Kecamatan Gedangan, Kabupaten Malang.

\section{HASIL DAN PEMBAHASAN Kerentanan Wilayah}

Hasil dari pemetaan ini dapat dilihat pada (Gambar 2) yang mengasumsikan bahwa ketinggian daratan yang kerang dari $10 \mathrm{~m}$ dikategorikan dalam kerentanan yang sangat tinggi. Dapat dilihat bahwa Desa Tumpakrejo yang memiliki panjang garis pantai yang paling pendek diantara dua desa lainnya memilki tingkat kerentanan yang sangat tinggi di sepanjang garis pantainya. Hal tersebut menandakan bahwa sepanjang garis pantai di Desa Tumpakrejo memiliki ketinggian daratan yang landai. Analisa tersebut sesuai dengan keadaan lapang dimana deretan pantai di Desa Tumpakrejo merupakan pantai berpasir yang memiliki ketinggian daratan yang rendah. Sedangkan di pesisir Desa Sindurejo dan Desa Gajahrejo dikategorikan dalam kerentanan sangat tinggi dan kerentanan tinggi, dimana pada survey lapang didapati deretan pantai berpasir dan pantai bertebing pada daerah tersebut. Luasan tingkat kerentanan ketiga desa tersebut bedasarkan ketinggian daratannya ditampilkan pada (Tabel 1).

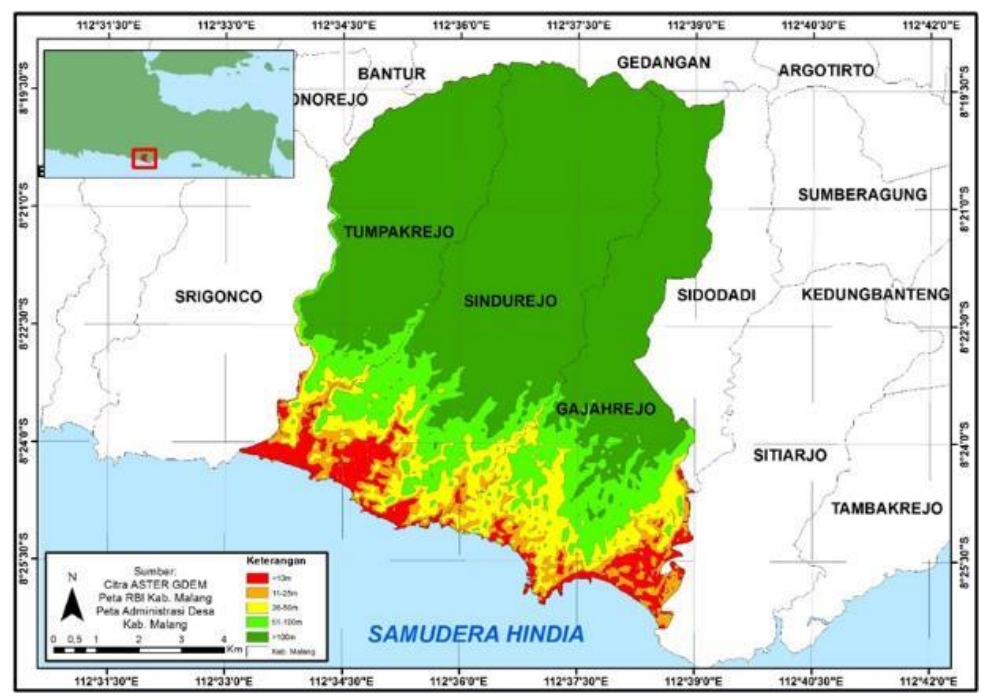

Gambar 2. Peta Kerentanan Berdasarkan Ketinggian Daratan

Tabel 1. Luas kelas kerentanan berdasarkan ketinggian daratan

\begin{tabular}{clccc}
\hline No & Tingkat Kerentanan & Ketinggian (m) & Luas (Ha) & Persentase (\%) \\
\hline 1 & Sangat tinggi & $<10 \mathrm{~m}$ & 487 & $5,13 \%$ \\
2 & Tinggi & $11-25 \mathrm{~m}$ & 476 & $5,01 \%$ \\
3 & Sedang & $26-50 \mathrm{~m}$ & 971 & $10,22 \%$ \\
4 & Rendah & $51-100 \mathrm{~m}$ & 1.305 & $13,73 \%$ \\
5 & Sangat rendah & $>100 \mathrm{~m}$ & 6.264 & $65,91 \%$ \\
\hline & & & $\mathbf{9 . 5 0 4}$ & $\mathbf{1 0 0} \%$
\end{tabular}

\section{Wilayah Lereng}

Berdasarkan Gambar 3. Dapat dilihat bahwa Wilayah desa pesisir Kecamatan Gedangan di dominasi oleh wilayah lereng yang termasuk dalam kategori kerentanan rendah, yaitu dengan kemiringan 16-40\%. Pada wilayah dekat pantai di Desa Tumpakrejo didominasi oleh kerentanan lereng kategori tinggi hingga sangat tinggi, yaitu dengan kemiringan $0-5 \%$. Sedangankan pada wilayah dekat pantai di Desa Sindurejo termasuk dalam kategori kerentanan tinggi hingga sangat tinggi di sebagian wilayah dan kategori sedang hingga rendah di sebagian wilayah yang lain. Berbeda halnya dengan Tumpakrejo, wilayah dekat pantai di Desa Gajahrejo yang memiliki garis pantai yang paling panjang dibandingkan dengan dua desa lainnya didominasi oleh tingkat kerentanan sedang hingga rendah yaitu dengan kemiringan $6-40 \%$. Sehingga dapat diasumsikan bahwa di daerah tersebut terdiri dari bukit, tebing atau dataran tinggi. Luasan daerah rentan berdasarkan kelerengannya ditampilkan pada (Tabel 2) 


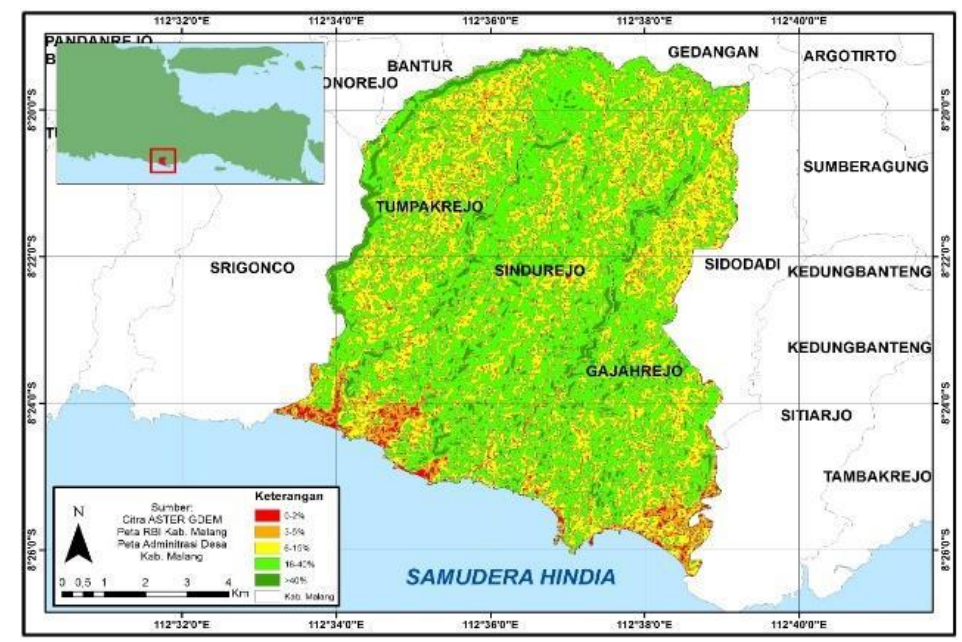

Gambar 3. Peta Kerentanan Berdasarkan Kelerengan Daratan

Tabel 2. Luas kelas kerentanan berdasarkan wilayah lereng

\begin{tabular}{clccc}
\hline No & Tingkat Kerentanan & Kelerengan (\%) & Luas (Ha) & Persentase (\%) \\
\hline 1 & Sangat tinggi & $0-2 \%$ & 189,87 & $2 \%$ \\
2 & Tinggi & $3-5 \%$ & 662,72 & $6,98 \%$ \\
3 & Sedang & $6-15 \%$ & $3.465,28$ & $36,48 \%$ \\
4 & Rendah & $16-40 \%$ & $4.813,38$ & $50,68 \%$ \\
5 & Sangat rendah & $>40 \%$ & 367,06 & $3,86 \%$ \\
\hline & & & $\mathbf{9 . 4 9 8 , 3 2}$ & $\mathbf{1 0 0} \%$ \\
\hline
\end{tabular}

\section{Jarak dari Garis Pantai}

Berdasarkan (Gambar 4) menunjukkan tingkat kerentanan wilayah berdasarkan jarak dari garis pantai. Menurut Diposaptono dan Budiman (2006), semakin dekat suatu wilayah terhadap laut makan akan semakin tinggi tingkat kerentanan dan resiko wilayah tersebut terhadap tsunami. Berdasarkan pengamatan di lapang menunjukkan bahwa pemukiman masyarakat pesisir di Kecamatan Gedangan berjarak 50-100 $\mathrm{m}$ dari bibir pantai.
Pemukiman yang mayoritas berada di pesisir berdiri diatas pantai berpasir yang sangat rentan terhadap tsunami. Kurangnya hutan pantai atau sabuk pantai (green belt) sebagai benteng pertahanan wilayah pesisir jika terjadi tsunami semakin meningkatkan tingkat kerentanan wilayah pesisir di kecamatan Gedangan. oleh karena itu perlu adanya penataan ruang yang baik untuk mengurangi resiko dampak jika terjaditsunami. Luas tingkat kerentanan berdasarkan jarak dari garis pantai adalah sebagai berikut (Tabel 3).

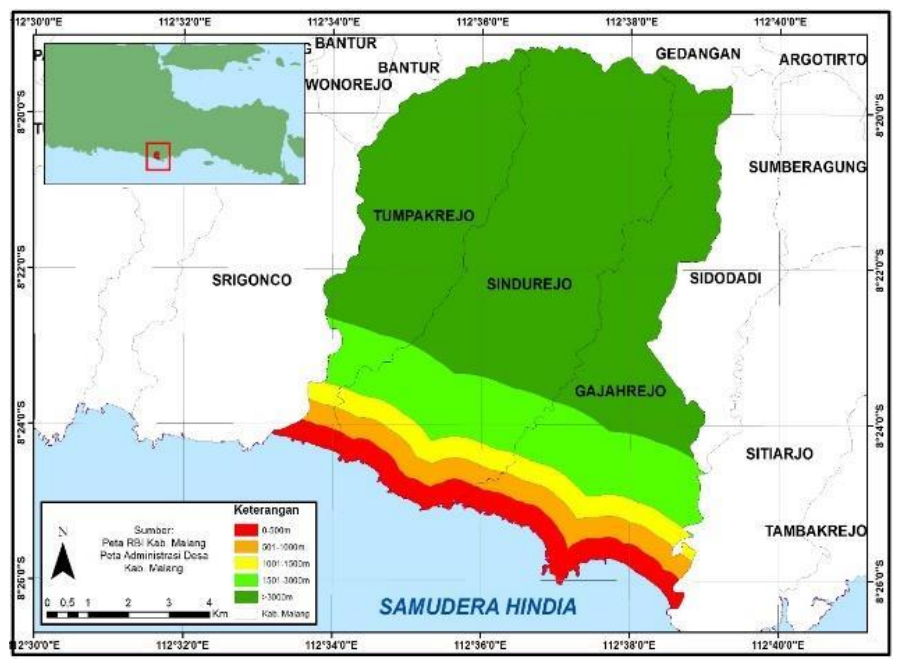

Gambar 4. Peta Kerentanan Berdasarkan Jarak Dari Garis Pantai 
Juvenil, 1(1), 19-28, (2020)

Tabel 3. Luas kelas kerentanan berdasarkan jarak dari garis pantai

\begin{tabular}{rlccc}
\hline No & Kerentanan & Jarak $(\mathbf{m})$ & Luas (Ha) & Persentase (\%) \\
\hline 1 & Sangat Tinggi & $0-500$ & 598,89 & $6,3 \%$ \\
2 & Tinggi & $501-1.000$ & 535,82 & $5,6 \%$ \\
3 & Sedang & $1.001-1.500$ & 522,29 & $5,5 \%$ \\
4 & Rendah & $1.501-3.000$ & $1.483,41$ & $15,6 \%$ \\
5 & Sangat rendah & $>3.000$ & $6.366,68$ & $67 \%$ \\
\hline \multicolumn{2}{r}{} & Total & $\mathbf{9 . 5 0 7 , 1 1}$ & $\mathbf{1 0 0} \%$ \\
\hline
\end{tabular}

\section{Jarak dari Badan Sungai}

Dapat dilihat pada (Gambar 5) bahwa wilayah pesisir Kecamtan Gedangan yang mencakup Desa Tumpakrejo, Desa Sindurejo dan Desa Gajahrejo memilki dua sungai besar yaitu Sungai yang berada di barat Desa Tumpakrejo dan satu sungai lagi berada di sebelah timur Desa Gajahrejo. Daerah tersebut memiliki tingkat kerentanan yang sangat tinggi terhadap tsunami karena daerah tersebut terdapat dua sungai besar yang dekat dengan muaranya dan berhadapan langsung dengan Samudera Hindia. Kondisi itulah yang menyebabkan daerah tersebut sangat rentan terhadap tsunami. Saat limpasan air bah tsunami masuk ke daratan, jika jarak antara kedua sungai dekat makan akan menimbulkan kerusakan yang lebih parah yang disebabkan oleh akumulasi energi gelombang tsunami dan massa air (Pedersen dan Glimsdal, 2010). Luas daerah kerentanan berdasarkan jarak dari garis pantai dapat dilihat pada (Tabel 4).



Gambar 5. Peta Kerentanan Berdasarkan Jarak Dari Badan Sungai

Tabel 4. Luas kelas kerentanan berdasarkan jarak dari sungai

\begin{tabular}{clccc}
\hline No & Tingkat Kerentanan & Jarak $(\mathbf{m})$ & Luas $(\mathbf{H a})$ & Persentase $(\%)$ \\
\hline 1 & Sangat tinggi & $0-100$ & 165,06 & $1,74 \%$ \\
2 & Tinggi & $101-200$ & 137,10 & $1,44 \%$ \\
3 & Sedang & $201-300$ & 134,29 & $1,41 \%$ \\
4 & Rendah & $301-500$ & 260,89 & $2,74 \%$ \\
5 & Sangat rendah & $>500$ & $8.809,76$ & $92,67 \%$ \\
\hline \multicolumn{2}{r}{ Total } & & $\mathbf{9 . 5 0 7 , 1 1}$ & $\mathbf{1 0 0} \%$ \\
\hline
\end{tabular}

\section{Tingkat Kerentanan}

Klasifikasi tingkat kerentanan tsunami di wilayah pesisir Kecamatan Gedangan dibagi menjadi lima kategori yaitu kerentanan sangat tinggi, kerentanan tinggi, kerentanan sedang, kerentanan rendah, dan kerentanan sangat rendah. Kategori kerentanansangat rendah dan kategori rendah mendominasi di ketiga desa. Wilayah dengan kerentanan rendah berada di bagian utara desa, hal tersebut dikarenakan bagian utara desa jaraknya jauh dengan pantai, 
jauh dengan muara sungai serta ketinggian dan kelerangannya yang tinggi. Table 5 .

Tabel 5. Luas kelas kerentanan

\begin{tabular}{clcc}
\hline No & \multicolumn{1}{c}{ Kerentanan } & Luas (Ha) & Persentase (\%) \\
\hline 1 & Sangat rendah & 188,63 & $1,98 \%$ \\
2 & Rendah & $7.470,46$ & $78,33 \%$ \\
3 & Sedang & $1.026,63$ & $10,76 \%$ \\
4 & Tinggi & 649,72 & $6,81 \%$ \\
5 & Sangat tinggi & 201,38 & $2,12 \%$ \\
\hline \multicolumn{2}{r}{ Total } & $\mathbf{1 0 0} \%$ \\
\hline
\end{tabular}

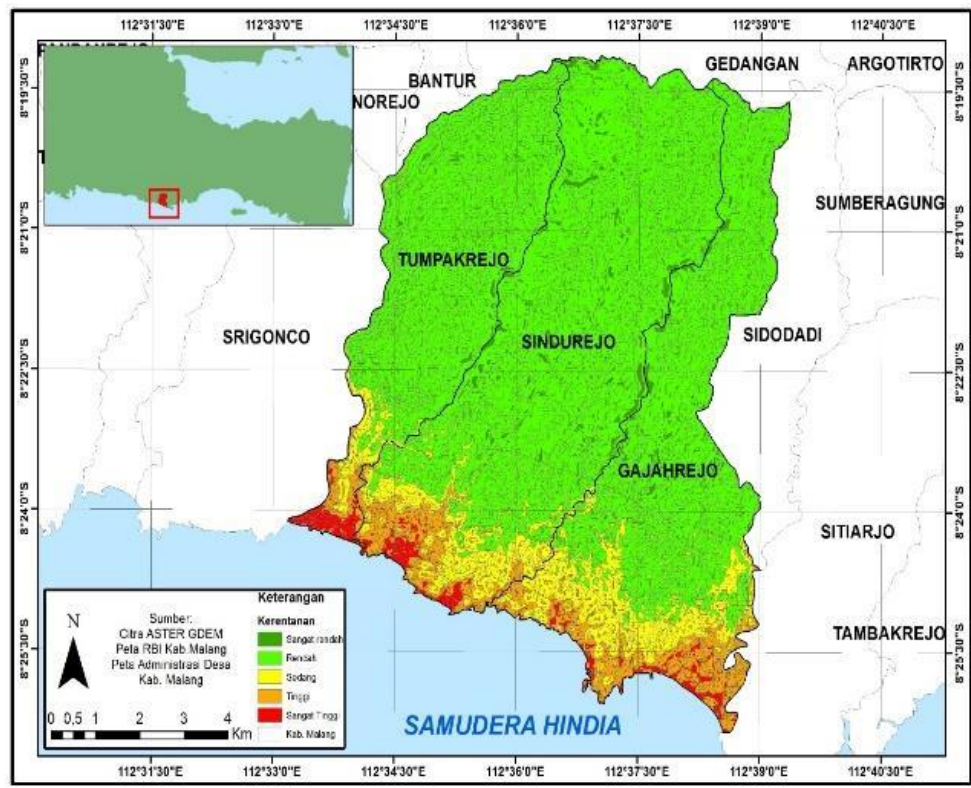

Gambar 6. Peta Kerentanan Terhadap Tsunami

Wilayah dengan kategori kerentanan tinggi hingga kerentanan sangat tinggi berada pada wilayah yang berjarak sekitar $0-150$ meter dari garis pantai. Daerah tersebut berada sangat dekat dengan pantai dan muara sungai. Lokasi yang sangat dekat dengan pantai menyebabkan wilayah tersebut akan merasakan dampak yang paling parah ketika terjadi bencana tsunami. Dengan ketinggian yang berkisar 0-10 meter dan kelerengan berkisar $0-2 \%$ menyebabkan tsunami akan leluasa untuk masuk ke wilayah tersebut dan menghancurkan segala sesuatu yang dilewatinya.

Keberadaan muara sungai juga akan memberikan dampak yang besar ketika terjadi menunjukkan luas dari masing-masing kelas kerentanan. 
Juvenil, 1(1), 19-28, (2020)

\begin{tabular}{llllllllll}
\hline Rataan & 2,62 & 2,66 & 3,24 & 2,51 & 3,21 & 3,25 & 3,47 & 2,35 \\
Standar Deviasi & 0,23 & 0,38 & 0,46 & 0,43 & 0,20 & 0,85 & 0,48 & 0,69 \\
\hline
\end{tabular}

Tabel 7. Indikator elemen ketahanan

\begin{tabular}{ll}
\hline Indikator & Elemen Ketahanan \\
\hline A & Pemerintah \\
B & Kehidupan Sosial dan Ekonomi \\
C & Manajemen Sumberdaya Pesisir \\
D & Desain Struktur dan Penggunaan Lahan \\
E & Pengetahuan tentang Risiko \\
F & Peringatan dan Evakuasi \\
G & Respon Terhadap Keadaan Darurat \\
H & Pemulihan Setelah Bencana \\
\hline
\end{tabular}

Nilai Resilience index yang ada, didapatkan resilience diagram (Gambar 7 ) yang nantinya akan dianalisis, pada elemen apa saja yang dinilai masihh dibawah standar, yang selanjutnya akan diberikan rekomendasi untuk meningkatkan ketahanan pada elemen tersebut.

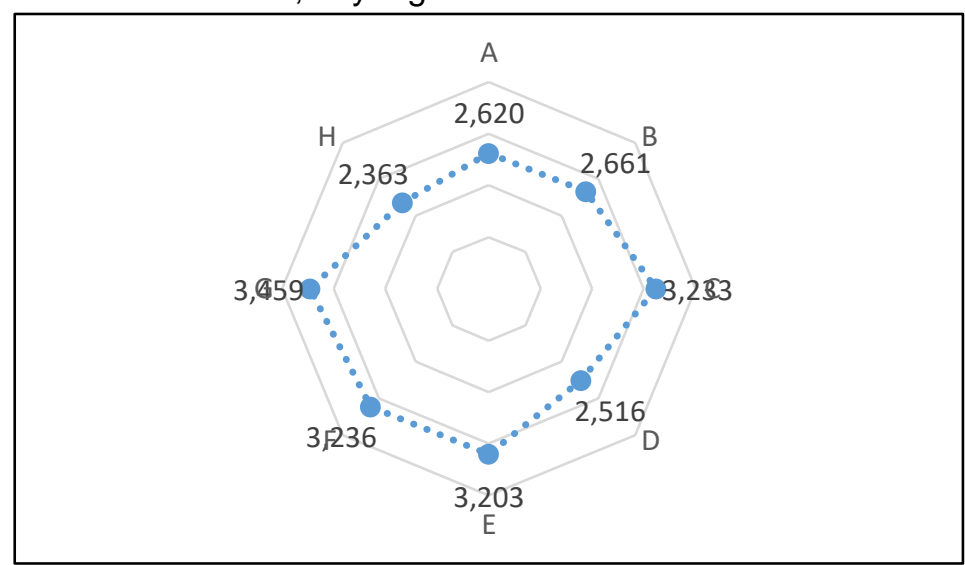

Gambar 7. Diagram Ketahanan Untuk Masyarakat Pesisir Kecamatan Gedangan

Untuk uji validitas, data penelitian dapat dikatakan valid jika $r$ hitung dari pertanyaan setiap elemen lebih besar dari nilai $r$ tabel. Dengan toleransi (a) sebesar 5\% dan responden sebanyak 80, maka diperoleh nilai $r$ tabel sebesar 0,22. Berdasarkan hasil uji dengan SPSS diketahui bahwa nilai $r$ hitung dari pertanyaan setiap elemen lebih besar dari nilai $r$ tabel $(0,22)$. Maka, dapat disimpilkan bahwa masing-masing pertanyaan untuk tiap elemen dalam kuesioner yang digunakan adalah valid.

Untuk uji reliabilitas, data penelitian dapat dikatakan reliabel jika nilai cronbach's alpha lebih besar dari 0,6. Berdasarkan hasil uji reliabilitas menggunakan SPSS didapatkan hasil cronbach's alpha sebesar 0,765, dimana nilai tersebut lebih besar dari 0,6. Hasil tersebut dapat dilihat bahwa semua indikator dalam penelitian adalah reliabel.
Berdasarkan uji validitas dan uji reliabilitas yang dilakukan, maka dapat disimpulkan bahwa kuesioner yang telah digunakan dan data yang diperoleh dalam penelitian ini layak digunakan dan telah memenuhi validitas dan reabilitas yang disyaratkan.

\section{Analis dan Rekomendasi}

Hasil data indeks ketahanan dan diagram ketahanan yang telah didapat diketahui bahwa elemen ketahanan yang nilainya masih di bawah standart dan harus ditinjau kembali adalah elemen Pemerintah dengan nilai 2,62, elemen Kehidupan Sosial dan Ekonomi dengan nilai 2,66, elemen Desain Struktur dan Penggunaan Lahan dengan nilai 2,52, dan elemen Pemulihan Setelah Bencana dengan nilai 2,36. Dapat dilihat bahwa dari delapan elemen ketahanan, lima diantaranya masih dibawah standart yang perlu adanya 
peninjauan kembali terhadap elemen ketahanan tersebut.

Hasil diatas menggambarkan bahwa ketahanan masyarakat di tiga desa pesisir Kecamatan Gedangan masih tergolong rendah. Maka dari itu perlu adanya upaya mitigasi untuk mengurangi resiko bencana tsunami dan

Tabel 8. Rekomendasi Mitigasi meningkatkan ketahanan atau kesiapan masyarakat pesisir dalam menghadapi bencana tsunami yang bisa datang kapan saja. Berikut adalah beberapa contoh studi kasus mitigasi bencana stunami di beberapa daerah yang dapat menjadi bahan rekomendasi, ditampilkan pada (Tabel 8).

\begin{tabular}{|c|c|c|}
\hline Lokasi & Ancaman/Bahaya & Strategi Mitigasi \\
\hline $\begin{array}{l}\text { Kabupaten Cilacap } \\
\text { (Mahendra et.al, 2013) }\end{array}$ & $\begin{array}{l}\text { - Gempa bumi dan } \\
\text { tsunami }\end{array}$ & $\begin{array}{l}\text { - } 2 \text { kali sosialisai mengenai } \\
\text { bencana gempa dan tsunami } \\
\text { - } 1 \text { kali simulasi tanggap bencana } \\
\text { di wilayah Pantai Teluk Penyu } \\
\text { dan pusat kota Kecamatan } \\
\text { Cilacap Selatan } \\
\text { - Pengetahuan tentang gempa } \\
\text { dan tsunami melalui mata } \\
\text { pelajaran di sekolah } \\
\text { Pemasangan sirine tower yang } \\
\text { diletakkan di kawasan pantai } \\
\text { wisata Widara Ayung dan } 6 \\
\text { masjid sebagai sirine evakuasi. } \\
\text { Peta evakuasi yang disertakan } \\
\text { dengan simbol berwarna yang } \\
\text { menandakan zona daerah } \\
\text { berdasarkan ketinggian } \\
\text { gelombangnya. }\end{array}$ \\
\hline $\begin{array}{l}\text { Kabupaten Pacitan } \\
\text { (Pradana, 2012) }\end{array}$ & - Tsunami & $\begin{array}{l}\text { - Telah dilakukan } 3 \text { kali sosialisasi } \\
\text { secara langsung dan melalui } \\
\text { sekolah-sekolah. } \\
\text { - } 2 \text { kali simulasi yang dilakuakan } \\
\text { di Pantai Telang Ria. } \\
\text { - } \quad \text { Perusahaan lokal mengadakan } \\
\text { pendidikan evakuasi tsunami } \\
\text { berupa pelatihan kepada calon } \\
\text { pegawai dan silabus } \\
\text { perusahaan. } \\
\text { - Sistem muster point yang } \\
\text { terletak di alun-alun Pacitan. } \\
\text { Dibentuk posko-posko taktis } \\
\text { yang disesuaikan dengan } \\
\text { wilayah dan tugasnya masing- } \\
\text { masing. }\end{array}$ \\
\hline
\end{tabular}




\section{KESIMPULAN DAN SARAN}

Parameter kerentanan yang berpengaruh sebanyak tiga parameter, dan satu parameter kerentanan kurang berpengaruh yaitu, jarak dari badan sungai. Tingkat kerentanan sangat rendah seluas 188,63 $\mathrm{Ha}$, rendah seluas $7.470,46 \mathrm{Ha}$, sedang seluas $1.026,63 \mathrm{Ha}$, tinggi seluas $649,72 \mathrm{Ha}$, dan sangat tinggi seluas 201,38 Ha. Terdapat empat elemen ketahanan yang masih bernilai di bawah standar (3) yaitu, elemen pemerintah, kehidupan sosial dan ekonomi, desain struktur dan penggunaan lahan, dan pemulihan setelah bencana.

\section{DAFTAR PUSTAKA}

Munir, A.Q. (2014). Sistem Informasi Geografi Pemetaan Bencana Alam Menggunakan Google Maps. Jurnal Teknologi Informasi, 9(26), 1-10

Nur, A. M. (2010). Gempa Bumi, Tsunami Dan Mitigasinya. Jurnal Geografi: Media Informasi Pengembangan dan Profesi Kegeografian, 7(1), 66-73.

Prijana. (2005). Metode Sampling Terapan untuk Penelitian Sosial. Humaniora, Bandung.

Hadi, F. dan Damayanti, A. (2017). Aplikasi Sig Untuk Pemetaan Zona Keterpaparan Permukiman Terhadap Tsunami Studi Kasus: Kota Pariaman, Sumatera Barat. Seminar Nasional Geomatika 2017: Inovasi Teknologi Penyediaan Informasi Geospasial untuk Pembangunan Berkelanjutan.

Kecamatan Gedangan dalam Angka Tahun 2018

US-IOTWS. (2007). How Resilient Is Your Coastal Community? - A Guide for Evaluating Coastal Community Resilience to Tsunamis and Other Hazards, NOAA Bangkok, Thailand.

Diposaptono, S., dan Budiman. (2006). Tsunami. Bogor: Sarana Komunikasi Utama. 